Fourth International Conference on Sustainable Construction Materials and Technologies http://www.claisse.info/Proceedings.htm

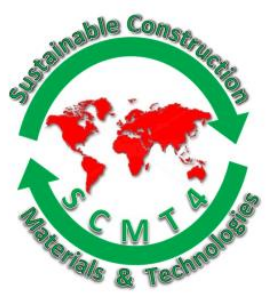

SCMT4

Las Vegas, USA, August 7-11, 2016

\title{
Effect of Combined Nanosilica and Microsilica on Resistance to Sulfate Attack
}

\author{
Nader Ghafoori $^{1 \mathrm{a}}$, Iani Batilov ${ }^{1 \mathrm{~b}}$, Meysam Najimi ${ }^{1 \mathrm{c}}$, MohammadReza Sharbaf ${ }^{1 \mathrm{~d}}$ \\ ${ }^{1}$ University of Nevada, Civil and Environmental Engineering and Construction, 4505 S Maryland Pkwy, \\ Las Vegas, NV 89154-4015, ${ }^{l a}$ Professor, Email: <nader.ghafoori@unlv.edu>, ${ }^{1 b}$ M.Sc. Student, Email: \\ <batilovi@unlv.nevada.edu>, ${ }^{1 c} P h . D . C a n d i d a t e, E m a i l:<n a j i m i m @ u n l v . n e v a d a . e d u>$, \\ ${ }^{1 b}$ M.Sc. Student, Email: <sharbaf@unlv.nevada.edu>
}

\begin{abstract}
In this study, the effect of combined nanosilica $(\mathrm{nS})$ and microsilica $(\mathrm{mS})$ on sulfate resistance of Portland cement (PC) mortars was evaluated against all cement control mortars and mixtures with equivalent contents of only one form of silica. Silica contained mortars had $6 \%$ cement replacement of either $\mathrm{nS}, \mathrm{mS}$, or $3 \%$ of each. An additional mixture with $3 \% \mathrm{mS}$ was also tested. The series of mortars were prepared with both a moderate $\mathrm{C}_{3} \mathrm{~A}(7.2 \%)$ and a low $\mathrm{C}_{3} \mathrm{~A}(4.1 \%)$ cement to evaluate the effectiveness of each silica replacement paired with a chemically sulfate and non-sulfate resistant cement. The mortars in this study were subjected to a 1.5 year period of full submersion sulfate attack in a $5 \%$ sodium sulfate $\left(\mathrm{Na}_{2} \mathrm{SO}_{4}\right)$ solution. The mortars tested were measured for expansion and compressive strength. Additional testing for absorption, rapid sulfate penetration, and mercury porosimetry of select mortar mixtures paired with laser diffraction particle analysis of the suspended silica particles supplemented the interpretation and explanation of the results. The expansion measurements indicated that $\mathrm{mS}$ replacement mortars outperform both $\mathrm{nS}$ only, and $\mathrm{nS}+\mathrm{mS}$ combination replacement mixtures. A negative effect of the dry $\mathrm{nS}$ powder replacement attributed to agglomeration of its fine sized silica particles during mixing negated the expected superior pozzolanic activity of the nanomaterial. In the case of the low $\mathrm{C}_{3} \mathrm{~A}$ sulfate resistant cement, the dry $\mathrm{nS}$ replacement of $6 \%$ exhibited more expansion than the control. The $\mathrm{nS}+\mathrm{mS}$ combination mortar mixtures for both cement types performed better than those with $\mathrm{nS}$ only but not better than the $\mathrm{mS}$ only mortars. Combining both silica types did not merge the strengths of both forms of pozzolan admixtures as hypothesized. In light of the results most of the beneficial contribution from the cement replacement with the combination mixtures could be attributed to the $\mathrm{mS}$ proportion given that the combination mixtures' expansion performance was comparable to that of the $3 \% \mathrm{mS}$ only mortars.
\end{abstract}




\section{INTRODUCTION}

Concrete's versatility and broad application in all aspects of civilized infrastructure and the built world means that twice as much of it is used in comparison to all other construction materials combined (Kosmatka \& Wilson 2016). Cement manufacturing is an energy and resource intensive process that accounts for approximately $1.1 \%$ of the US national greenhouse gas emissions, equal to more than 75 million metric tons of $\mathrm{CO}_{2}$ equivalents (Kosmatka \& Wilson 2016). There is a continuous effort to improve the sustainability and energy efficiency of both the production of cement, and concrete itself as a material. One strategy is the use of supplementary cementitious materials (SCMs) to improve the durability performance of concrete. Durable concrete made through the use of SCMs lessens concrete's environmental impact by both reducing the amount of virgin cement used and prolonging the service life of the structure, which saves on energy and resources associated with its maintenance, repair, and untimely replacement.

Durability of concrete in most applications is synonymous with quality concrete. Quality concrete needs to be capable of resisting a host of chemical and physical phenomenon one of which is sulfate attack. While sulfate attack alone may not be sufficient enough to cause complete failure; its effect on concrete such as expansive stress induced cracking, spalling, paste decalcification, increasing of porosity and permeability, can facilitate and aggravate a host of other deteriorative phenomena such as carbonation, freeze-and-thaw damage and reinforcement corrosion. Internal and external sulfate sources, as well as causes and effects of sulfate attack are well detailed in existing literature (Skalny et al. 2002; Hewlett \& Massazza 2003). Among the SCMs recommended for mitigating chemical sulfate attack by authorities in the industry such as ACI Committee 201, is microsilica (mS), a by-product of the silicon and ferrosilicon smelting industries (ACI Committee 201 2008). The sulfate attack mitigating effects of $\mathrm{mS}$ are that it reduces overall permeability by densifying the cement paste and interfacial transition zone (ITZ) with the aggregate, and reduces the available hydration product calcium hydroxide $\mathrm{Ca}(\mathrm{OH})_{2}$ by reacting with it and forming secondary $\mathrm{C}-\mathrm{S}-\mathrm{H}$. This pozzolanic reaction, paired with a reduction of the available $\mathrm{C}_{3} \mathrm{~A}$ due to replacement of the cement with microsilica, deters the precipitation of excessive gypsum and expansive ettringite which depend on a steady supply of calcium, hydroxide, and sulfate ions (Hewlett \& Massazza 2003; Skalny et al. 2002).

There has been an exponentially growing interest in learning and understanding the relationship between the nanostructure of the cementitious matrix and its impact on the properties, behavior and performance of concrete (Campillo et al. 2004). With the development of the tools and technology to study concrete at this nanoscale came a wave of new research and testing of the application of a host of new synthesized nanoscale SCMs (Sobolev \& Gutiérrez 2005). One of the first to gain attention and most widely used has been nanosilica $(\mathrm{nS})$, essentially nano-sized $(<100 \mathrm{~nm})$ silicon dioxide $\left(\mathrm{SiO}_{2}\right)$ particles. The particles of $\mathrm{mS}$ are larger in comparison to $\mathrm{nS}$, but typically $<1 \mu \mathrm{m}$ (Holland 2005). The smaller particle sizes of $\mathrm{nS}$ correlate with a specific surface area of $80 \mathrm{~m}^{2} / \mathrm{g}$ or more while that of $\mathrm{mS}$ is typically $15-25 \mathrm{~m}^{2} / \mathrm{g}$ (Campillo et al. 2004). This high surface area makes $\mathrm{nS}$ a much more reactive pozzolan that consumes $\mathrm{Ca}(\mathrm{OH})_{2}$ faster than $\mathrm{mS}$. This makes $\mathrm{nS}$ suitable to pair up with other SCMs such as fly ash to compensate for its slow rate of strength development (Said et al. 2012). During hydration, $\mathrm{nS}$ forms seeding sites from the additional $\mathrm{C}-\mathrm{S}-\mathrm{H}$ it generates and stimulates the growth of a much more compact $\mathrm{C}-\mathrm{S}-\mathrm{H}$ phase that is not limited to growing on the grain surface of the hydrating alite $\left(\mathrm{C}_{3} \mathrm{~S}\right)$, it starts growing in the pore spaces as well (Singh et al. 2013). Additionally, since $\mathrm{nS}$ also rapidly consumes free $\mathrm{Ca}^{+}$ions freed from the dissolution of $\mathrm{Ca}(\mathrm{OH})_{2}$ to produce secondary C-S-H, it prevents calcium leaching much faster than $\mathrm{mS}$, especially if the concrete is exposed to sulfates during an early age. Given these observations the authors set out to test the effectiveness of combining $\mathrm{mS}$ and $\mathrm{nS}$ against sulfate attack to 
see if $\mathrm{nS}$ can complement $\mathrm{mS}$ as a filler at the nanoscale level, and as an aggressive pozzolan that can help $\mathrm{mS}$ in developing a more sulfate resistant and impermeable mortar. Beyond densifying the paste and ITZ, the nS could react with more of the $\mathrm{Ca}(\mathrm{OH})_{2}$ before sulfate ions react with it to form gypsum and consecutively ettringite which should also manifest in a reduced expansion and ion diffusivity.

\section{EXPERIMENTAL PROGRAM}

The mortars in this study were subjected to a 79 week ( 1.5 year) full submersion exposure in a $5 \%$ sodium sulfate $\left(\mathrm{Na}_{2} \mathrm{SO}_{4}\right)$ solution. The linear expansion of mortar bars, mortar cube compressive strength, water absorption, and rapid sulfate ion penetration (RSPT) were measured.

Materials. Mortars were prepared with two locally sourced cements with contrastingly different $\mathrm{C}_{3} \mathrm{~A}$ contents. Cement $\mathrm{L}$ was a Type V low alkali cement that contained $4.1 \% \mathrm{C}_{3} \mathrm{~A}$. Cement $\mathrm{M}$ was a Type I cement that contained $7.2 \% \mathrm{C}_{3} \mathrm{~A}$. The chemical and physical properties of the cements are presented in Table 1 .

The $\mathrm{nS}$ used was supplied as a porous white dry powder form with particle sizes ranging from $15-20 \mathrm{~nm}$ and a specific surface area of $640 \mathrm{~m}^{2} / \mathrm{g}$. It was mechanically blended with the premeasured mixing water for 1 minute prior to use in each mortar mixture. The $\mathrm{mS}$ used in the experiment, was a gray amorphous sub-micron powder and was homogeneously intermixed with the cement for each mortar mixture. The chemical and physical properties of the nano- and microsilica are also presented in Table 1. A polycarboxylate based high-range water-reducing admixture (HRWRA) was utilized for achieving the desired flow per ASTM C 109.

Table 1. Chemical Composition and Physical Properties of Cement and nS

\begin{tabular}{|c|c|c|c|c|}
\hline & $\begin{array}{c}\text { Cement } \mathrm{A} \\
\left(\text { Moderate } \mathrm{C}_{3} \mathrm{~A}\right)\end{array}$ & $\begin{array}{l}\text { Cement B } \\
\left(\text { Low } C_{3} A\right)\end{array}$ & $\begin{array}{l}\text { micro- } \\
\text { Silica } \\
(\mathrm{mS})\end{array}$ & $\begin{array}{c}\text { Dry Powder } \\
\text { nano-Silica } \\
(\mathrm{nS})\end{array}$ \\
\hline \multicolumn{5}{|l|}{ "Chemical Composition } \\
\hline Silicon Dioxide $\left(\mathrm{SiO}_{2}\right), \%$ & 21.1 & 21.7 & 94.72 & 99.5 \\
\hline Aluminum Oxide $\left(\mathrm{Al}_{2} \mathrm{O}_{3}\right), \%$ & 4 & 4.1 & -- & 0.002 \\
\hline Ferric Oxide $\left(\mathrm{Fe}_{2} \mathrm{O}_{3}\right), \%$ & 2 & 4.0 & -- & 0.001 \\
\hline Calcium Oxide $(\mathrm{CaO}), \%$ & 62.7 & 63.2 & -- & 0.002 \\
\hline Magnesium Oxide $(\mathrm{MgO}), \%$ & 2.1 & 2.8 & -- & 0.001 \\
\hline Sulfur Trioxide $\left(\mathrm{SO}_{3}\right), \%$ & 2.8 & 1.8 & 0.23 & -- \\
\hline Loss on Ignition, \% & 1.8 & 0.7 & 2.82 & -- \\
\hline Insoluble Residue, \% & 0.71 & 0.1 & -- & -- \\
\hline Total Alkali $\left(\mathrm{Na}_{2} \mathrm{O}+\mathrm{K}_{2} \mathrm{O}\right), \%$ & 0.59 & 0.46 & 0.49 & -- \\
\hline Free Lime $(\mathrm{CaO}), \%$ & 0 & 0.8 & & \\
\hline \multicolumn{5}{|l|}{ Physical Properties } \\
\hline Time of Set Initial Vicat, min & 145 & 150 & -- & -- \\
\hline Specific Surface Area, $\mathrm{m}^{2} / \mathrm{g}$ & $0.341^{\mathrm{a}}$ & $0.285^{\mathrm{a}}$ & $22.65^{\mathrm{b}}$ & $640^{\mathrm{b}}$ \\
\hline 325 Mesh $(45 \mu \mathrm{m}), \%$ passing & -- & 72.9 & 97.12 & \\
\hline Avg. Particle Size (APS), $\mu \mathrm{m}$ & $20-30^{c}$ & $35-45^{\mathrm{c}}$ & $0.1-1.0^{\mathrm{c}}$ & $0.015-0.020$ \\
\hline \multicolumn{5}{|l|}{ Per Bogue Calculation ${ }^{d}$} \\
\hline Tricalcium Silicate $\left(\mathrm{C}_{3} \mathrm{~S}\right), \%$ & 57.0 & 54.0 & -- & -- \\
\hline Dicalcium Silicate $\left(\mathrm{C}_{2} \mathrm{~S}\right), \%$ & 17.5 & 21.5 & -- & -- \\
\hline Tricalcium Aluminate $\left(\mathrm{C}_{3} \mathrm{~A}\right), \%$ & 7.2 & 4.1 & -- & -- \\
\hline Tetracalcium Aluminoferrite $\left(\mathrm{C}_{4} \mathrm{AF}\right), \%$ & 6.1 & 12.2 & -- & -- \\
\hline
\end{tabular}

${ }^{a}$ by Blaine air-permeability test $\quad$ by BET Analysis

${ }^{c}$ Estimated from MasterSizer Particle Distribution Analysis 
${ }^{\mathrm{d} B o g u e ~ M o d i f i e d ~ E q u a t i o n ~ f o r ~ I n t e r g r o u n d ~ G y p s u m ~ \& ~ L i m e s t o n e ~(W i n t e r ~ 2012) ~}$

The fine aggregate used for the mortars in this study was from a Nevada based quarry and had an ovendry specific gravity of 2.76 , absorption of $0.81 \%$ and a fineness modulus of 2.64. Its gradation was well inside the upper and lower limits of ASTM C 33. Mortar mixing water and water used for the preparation of the sodium sulfate solution was commercially bottled distilled water obtained from a single source.

Mixture Proportions. The mixture proportions of the mortars tested are presented in Table 2. Besides the control mixture for each cement type, there were 4 mortars mixtures with a total of $3 \%$ or $6 \%$ cement replacement with either $3 \% \mathrm{mS}$ only ( $\mathrm{L} 3 \mathrm{mS}$ and $\mathrm{M} 3 \mathrm{mS}), 6 \% \mathrm{mS}$ only ( $6 \mathrm{mS}$ and $\mathrm{M} 6 \mathrm{mS}), 6 \% \mathrm{nS}$ only (L6nS and M6nS), or an equal 3\% proportion of each form of silica ( $\mathrm{L} 3 \mathrm{mS}+3 \mathrm{nS}$ and $\mathrm{M} 3 \mathrm{mS}+3 \mathrm{nS})$.

Table 2. Mortar Mixture Proportions

\begin{tabular}{lcccccc}
\hline \multirow{2}{*}{$\begin{array}{l}\text { Sample } \\
\text { Designation }\end{array}$} & \multicolumn{3}{c}{ Binder, \% } & Measured & \multicolumn{3}{c}{$\begin{array}{c}\text { 3-Day Compressive Strength, } \\
\text { MPa }\end{array}$} \\
\cline { 2 - 6 } & Cement & $\mathrm{nS}$ & $\mathrm{mS}$ & Flow, \%* & \\
\hline \hline Low C 3 A Cement L & & & & & & \\
\hline L0 & 100 & 0 & 0 & 145 & 26.6 & 3,851 \\
L3mS & 97 & 0 & 3 & 127 & 23.9 & 3,463 \\
L6mS & 94 & 0 & 6 & 97 & 23.6 & 3,419 \\
L6nS & 94 & 6 & 0 & 102 & 22.2 & 3,226 \\
L3mS+3nS & 94 & 3 & 3 & 98 & 24.2 & 3,504 \\
\hline \hline Moderate C C Cement M & & & & & \\
\hline M0 & 100 & 0 & 0 & 148 & 29.6 & 4,296 \\
M3mS & 97 & 0 & 3 & 108 & 30.5 & 4,420 \\
M6mS & 94 & 0 & 6 & 95 & 30.8 & 4,463 \\
M6nS & 94 & 6 & 0 & 100 & 29.9 & 4,337 \\
M3mS+3nS & 94 & 3 & 3 & 102 & 30.1 & 4,363 \\
\hline \hline
\end{tabular}

*Flow measured according to ASTM C 1437 with flow table conforming to ASTM C 230

The (w/b) was kept at a constant 0.485 for all mixtures according to ASTM C 1012. The fine aggregateto-binder ratio was 2.75-to-1 by mass as specified in ASTM C 109.

Mixing Procedure. Mortar mixtures were batched using an electrically driven epicyclic mechanical mixer following the mortar preparation procedure of ASTM C 305. The mixing procedure began with either blending the $\mathrm{nS}$ with the mixing water for 1 minute in a commercial blender or hand mixing the $\mathrm{mS}$ with the dry cement prior to placing in the mixer. For each testing mixture, 4 mortar expansion bars were prepared per ASTM C 1012 and 36, $5 \mathrm{~cm}$ (2-in), mortar cubes specimens were prepared per ASTM C 109 for strength testing. Additionally multiple $10 \mathrm{~cm}$ (4-in), diameter disks were made for supplemental testing. For the $\mathrm{nS}$ and $\mathrm{mS}$ replacement mixtures, the HRWRA was utilized as required to reach the ASTM C 109 recommended flow of $110 \pm 5 \%$.

All mortar sample molds were hand packed and compacted using an electromagnetic vibrating table. The sample molds for each mortar mixture were plastic wrapped and kept at room temperature $\left(21 \pm 3{ }^{\circ} \mathrm{C}\right)$ for 24 hours then followed by 3 days of curing in a moist room to achieve the required compressive strength of $20 \pm 1.0 \mathrm{MPa}(2900 \pm 145 \mathrm{psi})$ per ASTM C 1012 prior to sulfate exposure. After the 3 days of moist room curing, three mortar cubes were tested for compression strength to confirm the required minimum strength. Following the 3 day curing period, the mortar bars and half of the mortar cubes were transferred to 5\% sodium sulfate solution tanks. The remaining cubes were kept in the moist curing room and tested in compression at the same age of samples immersed in sulfate solution. 
Sulfate Solution. The $5 \% \mathrm{Na}_{2} \mathrm{SO}_{4}$ solution was prepared per ASTM C 1012. Sufficient solution was prepared for each container to maintain the recommended minimum solution to mortar volume ratio of 4 . The solution in each container was kept in circulation using submersible pumps. To replenish the sulfate ion concentration in the solution (Mehta 1975), the solution $\mathrm{pH}$ was manually rebalanced to $7.0 \pm 1$ daily with $0.5 \mathrm{~N} \mathrm{H}_{2} \mathrm{SO}_{4}$ for the first 6 months and then weekly for the remainder of the 1.5 year fully submerged test.

Absorption and RSPT. All absorption testing was performed with three mortar disks per ASTM C 642 to find the average reading presented in the results. The RSPT test, as proposed in the Sulfate-Resisting Concrete report by the Cement Concrete \& Aggregates Australia (CCAA 2011), is similarly setup to the traditional rapid chloride permeability test (RCPT) per ASTM C1202. In this study, a $10 \% \mathrm{Na}_{2} \mathrm{SO}_{4}$ solution was used across the $0.3 \mathrm{~N} \mathrm{NaOH}$ instead of $3 \% \mathrm{NaCl}$; similar to absorption, three mortar disks were used for each average diffusivity reading presented in the results.

\section{RESULTS AND DISCUSSION}

The expansion readings at key milestones along the 1.5 year test are reported in Table 3 for convenient reference during the discussion of results.

Table 3. Expansion Measurements at Key Time Periods

\begin{tabular}{|c|c|c|c|c|c|}
\hline & M0 & M3mS & M6mS & M6nS & $\mathrm{M} 3 \mathrm{mS}+3 \mathrm{nS}$ \\
\hline 4 WEEKS & $0.011 \%$ & $0.009 \%$ & $0.010 \%$ & $0.012 \%$ & $0.007 \%$ \\
\hline 8 WEEKS & $0.016 \%$ & $0.012 \%$ & $0.015 \%$ & $0.019 \%$ & $0.011 \%$ \\
\hline 12 WEEKS & $0.021 \%$ & $0.017 \%$ & $0.017 \%$ & $0.021 \%$ & $0.014 \%$ \\
\hline 26 WEEKS & $0.039 \%$ & $0.028 \%$ & $0.028 \%$ & $0.034 \%$ & $0.027 \%$ \\
\hline 1 YEAR & $0.074 \%$ & $0.045 \%$ & $0.043 \%$ & $0.054 \%$ & $0.045 \%$ \\
\hline \multirow[t]{2}{*}{ 1.5 YEAR } & $0.124 \%$ & $0.056 \%$ & $0.050 \%$ & $0.063 \%$ & $0.058 \%$ \\
\hline & LO & L3mS & L6mS & L6nS & $\mathrm{L3mS}+3 \mathrm{nS}$ \\
\hline 4 WEEKS & $0.009 \%$ & $0.006 \%$ & $0.003 \%$ & $0.009 \%$ & $0.008 \%$ \\
\hline 8 WEEKS & $0.013 \%$ & $0.010 \%$ & $0.011 \%$ & $0.012 \%$ & $0.010 \%$ \\
\hline 12 WEEKS & $0.014 \%$ & $0.011 \%$ & $0.012 \%$ & $0.015 \%$ & $0.013 \%$ \\
\hline 26 WEEKS & $0.029 \%$ & $0.024 \%$ & $0.025 \%$ & $0.032 \%$ & $0.025 \%$ \\
\hline 1 YEAR & $0.047 \%$ & $0.041 \%$ & $0.037 \%$ & $0.050 \%$ & $0.038 \%$ \\
\hline 1.5 YEAR & $0.059 \%$ & $0.052 \%$ & $0.047 \%$ & $0.061 \%$ & $0.048 \%$ \\
\hline
\end{tabular}

Through comparison of the control mixtures' expansion of both cement types it is evident how significantly different both cements perform under chemical sodium sulfate attack. True to expectations, the low $\mathrm{C}_{3} \mathrm{~A}$ control mixture L0 outperforms the moderate $\mathrm{C}_{3} \mathrm{~A}$ control mortar M0. At one year, L0 exhibits $44 \%$ less expansion than M0. That percent difference increases to $71 \%$ at the conclusion of the test. As the sulfate solution permeated deeper into the mortar bars and the aluminate phase monosulfate, calcium and sulfate ions became more abundant, the more favorable $\mathrm{C}_{3} \mathrm{~A}$ conditions stood out in the expansion behavior and the differences between the two mixtures quickly became apparent.

With the moderate $\mathrm{C}_{3} \mathrm{~A}$ cement series, all silica replacements by the end of the test period had a positive impact on reducing the rate and level of expansion as presented in Figure 1. Contrary to expectations, the $\mathrm{nS}$ mixtures' expected superior performance over their $\mathrm{mS}$ counterparts was not observed. Out of all silica replacement mortars for this cement, the $6 \% \mathrm{nS}$ replacement mixture M6nS exhibited the most expansion after the control. In fact, the control mortar performed better during the first 8 weeks as can be seen in 
Table 3 before the M6nS expansion readings dropped below those of M0. At 4 weeks, the M0 measured expansion was $0.011 \%$ versus $0.012 \%$ measured for M6nS, a 9\% difference. By 8 weeks M0 had $0.016 \%$ and M6nS $0.019 \%$, the difference increased to $16 \%$. The $\mathrm{mS}$ replacement mortars outperformed M6nS, including $\mathrm{M} 3 \mathrm{mS}$ which had half the cement replacement of M6nS. This trend was consistent at early age and through the conclusion of the test. At 4 weeks, M3mS showed an expansion of $0.009 \%$, which compared against the $0.012 \%$ of M6nS, was 36\% better. Although M6nS narrowed the difference over time, at 1 year, M3mS outperformed M6nS by $18 \%$, and then $11 \%$ at 1.5 years. As evident, the dry $\mathrm{nS}$ had a negative impact on the expansion performance of the mortar.

The expectation that equal replacements of $\mathrm{nS}$ and $\mathrm{mS}$ in $\mathrm{M} 3 \mathrm{nS}+\mathrm{mS}$ would combine the strengths of both forms of silica to create a more impermeable and sulfate resistant mixture than either pure form of replacement was also not met. As evident in Figure 1, M3mS+3nS outperformed M6nS but exhibited more expansion that M6mS. It did perform better than M6mS during the first 26 weeks, starting with a strong 39\%, 35\%, and 18\% improvement over M6mS at 4, 8, and 12 weeks respectively. By the $26^{\text {th }}$ week, $\mathrm{M} 3 \mathrm{mS}+3 \mathrm{nS}$ fell behind and concluded the test with $0.058 \%$ expansion versus the $0.050 \%$ measured for M6mS, the $\mathrm{mS}$ only mixture performed $16 \%$ better. As can be seen in Figure 1, with half the cement replacement, $\mathrm{M} 3 \mathrm{mS}$ performs almost as well as the combination mortar leading to the conclusion that most of the beneficial contribution to sulfate resistance in the combination mortar stems from the $\mathrm{mS}$ replacement. The positive contribution of dry $\mathrm{nS}$ replacement might be only that of reducing the overall availability of $\mathrm{C}_{3} \mathrm{~A}$ by reducing the cement content by another $3 \%$.

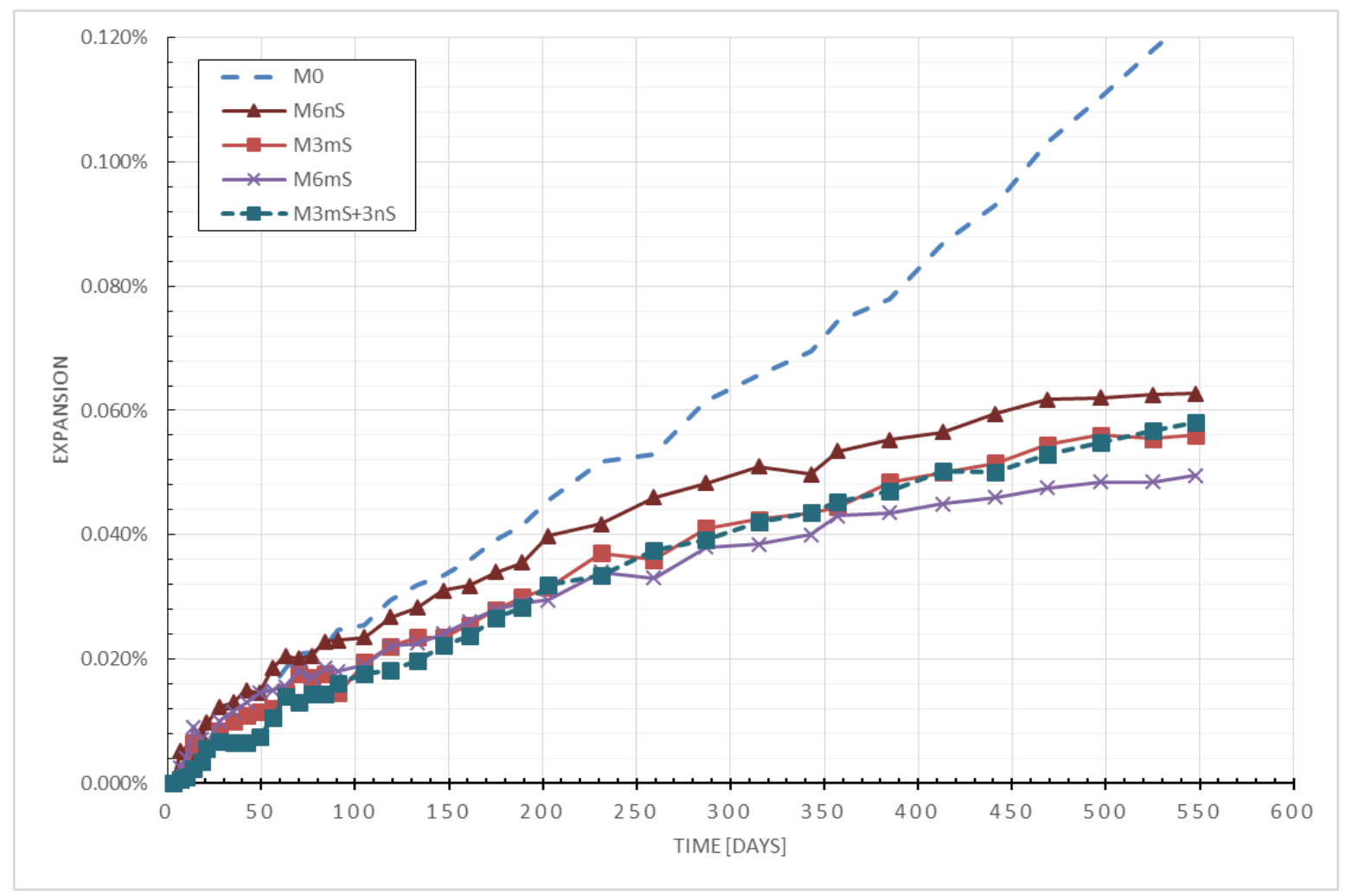

Figure 1. Expansion Measurements for Cement M Mortar Mixtures 
For the moderate $\mathrm{C}_{3} \mathrm{~A}$ cement $\mathrm{M}, \mathrm{nS}$ replacement proved deleterious, but the negative effects seemed further exasperated in the low $\mathrm{C}_{3} \mathrm{~A}$ cement $\mathrm{L}$ mortar mixture series presented in Figure 2. Cement $\mathrm{L}$ has $4.1 \% \mathrm{C}_{3} \mathrm{~A}$ which meets the 5\% limit imposed for Type $\mathrm{V}$ high sulfate resistance cements per ASTM C 150. As such, cement $\mathrm{L}$ is chemically resistant to sulfate attack and inherently more sensitive to any negative effects of the silica SCMs that might have been more subtle with cement M. After 12 weeks of sulfate exposure in the sodium sulfate tanks, the trend became clear, the $6 \% \mathrm{nS}$ mortar L6nS exhibited more expansion that the control L0. Up until then similarly to cement M, L6nS has a slight edge on the control, $0.012 \%$ for L6nS versus $0.013 \%$ for L0 at 8 weeks, and averaging around $4-5 \%$ improvement over the control. After the longer period of exposure, the trend reversed and L6nS consistently exhibited more expansion than the control (averaging 7\% more than L0). The rest of the silica replacement mixtures, $\mathrm{L} 3 \mathrm{mS}, \mathrm{L} 6 \mathrm{mS}$, and $\mathrm{L} 3 \mathrm{mS}+3 \mathrm{nS}$ outperformed the control as was the case with the cement $\mathrm{M}$ series. Also similar to cement $\mathrm{M}$, the $6 \% \mathrm{mS}$ mixture $\mathrm{L} 6 \mathrm{mS}$ outperformed all mortars in terms of the least expansion over the 1.5 year test. At 1 year, $\mathrm{L} 6 \mathrm{mS}$ had $0.037 \%$, and at 1.5 years, it had $0.047 \%$, which were $26 \%$ and $23 \%$ less than L0 respectively. Nevertheless with cement L, M6mS was in close competition with $\mathrm{L} 3 \mathrm{mS}+3 \mathrm{nS}$ and $\mathrm{L} 3 \mathrm{mS}$; usually less than $10 \%$ improvement over either. Similarly to cement $\mathrm{M}$, the combination replacement mixture $\mathrm{L} 3 \mathrm{mS}+3 \mathrm{nS}$, seemed to thread the needle between $\mathrm{L} 3 \mathrm{mS}$ and $\mathrm{L} 6 \mathrm{mS}$, performing on average $8 \%$ better than $\mathrm{L} 3 \mathrm{mS}$ but exhibiting expansion up to 5\% more than L6mS. Results indicate that with a sulfate resistant cement a smaller dose of $3 \% \mathrm{mS}$ is almost as effective as doubling it and with either cement combining dry $\mathrm{nS}$ with $\mathrm{mS}$ is not preferable to pure $\mathrm{mS}$. With cement $\mathrm{M}$ increasing the dose of $\mathrm{mS}$ proved more impactful to the mixture's sulfate resistance but doubling the replacement did not proportionally halve the measured expansion.

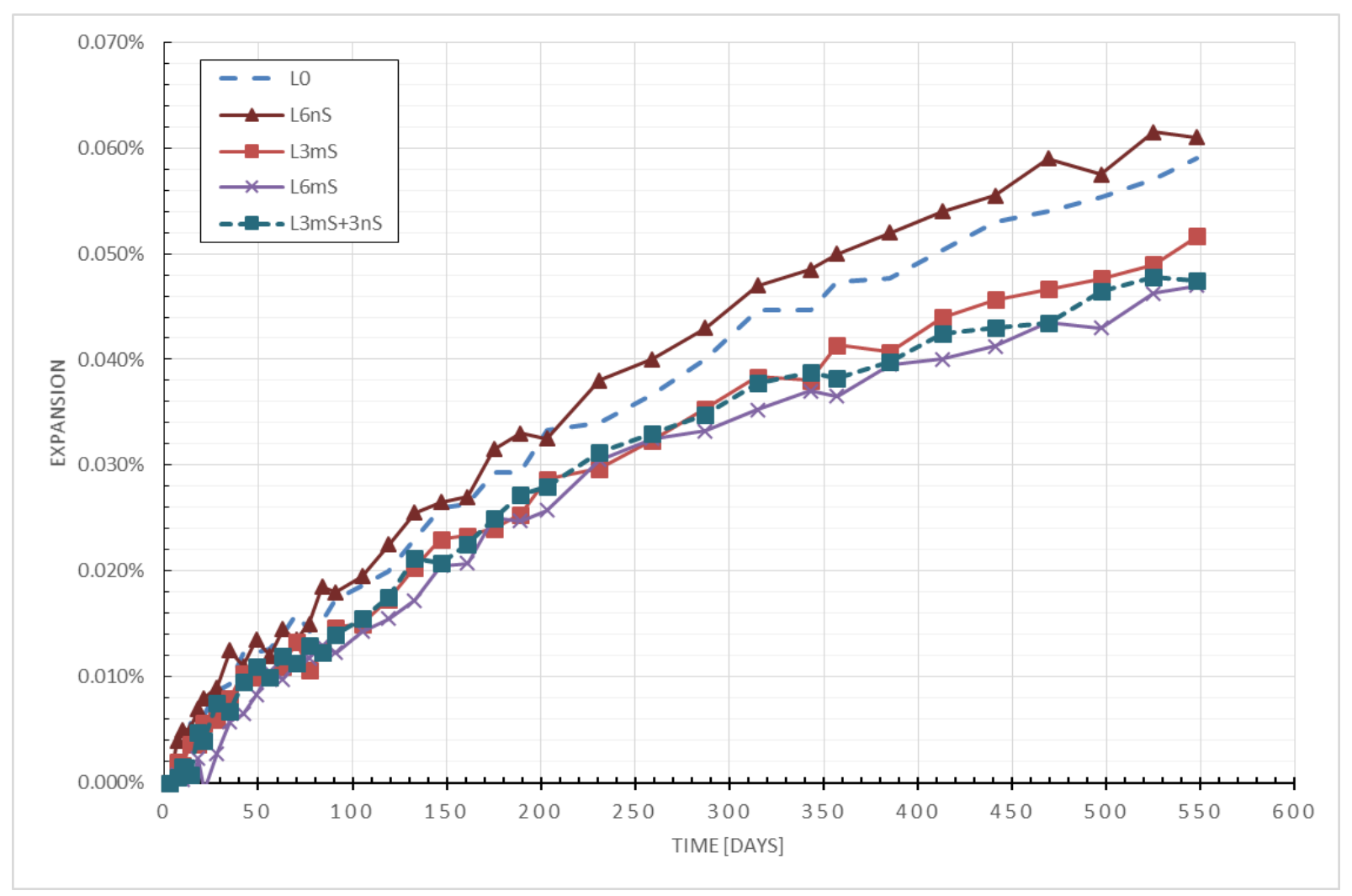

Figure 2. Expansion Measurements for Cement M Mortar Mixtures 
Sulfate expansion results indicated that $\mathrm{nS}$ replacement had a generally negative effect on the sulfate resistance of the mortar mixtures tested. To better understand why, the researchers turned to existing literature and supplemental testing. Other research with $\mathrm{nS}$ has revealed that due to its ultrafine particle size, it has an inherent tendency to agglomerate when introduced into a liquid (Senff et al. 2010; Quercia \& Brouwers 2010). This effect is characteristic of most ultrafine particles in the nanoscale range of 1 to $100 \mathrm{~nm}$, since they are sensitive to Van der Waals, capillary and electrostatic forces (Taurozzi et al. 2011). The stability of the nanoscale silica particles in the fluid system is greatly affected by the electrostatic charge on the solid particle surface which correlates to a particle fluid suspension measurement referred to as the zeta potential (Jiang et al. 2009). The zeta potential reflects the hydrodynamic diameter of the suspended particles and their potential for agglomeration. If the measured zeta potential absolute value is more than $30 \mathrm{mV}$, then the suspension is considered electrostatically stable. The zeta potential is sensitive to multiple variables of the solution one of which is the $\mathrm{pH}$. To electrostatically stabilize the solution the $\mathrm{pH}$ must be away from the isoeletric point by more than 2, the point at which the zeta potential is essentially null and attractive Van der Waal forces overcome electrostatic repulsion (Jiang et al. 2009; ISO 14887 2000). With $\mathrm{nS}$, that isoeletric point is between 2 and 2.5 (Sieger et al. 2004). Under the alkali environment of the cement hydration products which is ordinarily at a $\mathrm{pH}$ of around 12.5 (Neville 1998), the absolute value of the zeta potential for $\mathrm{nS}$ as measured by Shih et al. (2006) can be estimated to be approximately $50 \mathrm{mV}$. These conditions are favorable and the silica particles have a strong electro kinetic barrier that causes the particles to repel which tends to prevent agglomeration. This might be of little help if the $\mathrm{nS}$ introduced with the Portland cement is already in an agglomerated state.

Prior the introduction in the cement, the dry $\mathrm{nS}$ powder is blended with the distilled mixing water. Although pure water is neutral with a $\mathrm{pH}$ of 7 , distilled water tends to be acidic since when exposed to air it reacts with carbon dioxide from the atmosphere that forms a very diluted form of carbonic acid $\left(\mathrm{H}_{2} \mathrm{CO}_{3}\right)$. The carbonic acid releases hydrogen ions $\left(\mathrm{H}^{+}\right)$which can bring the $\mathrm{pH}$ of the distilled water down below 5 (Bibby Scientific n.d.). Therefore during mixing, the zeta potential of the $\mathrm{nS}$ particles in this environment will be lower. Test strip $\mathrm{pH}$ measurements taken of the distilled water used in this study indicated its $\mathrm{pH}$ was less than 6, see Figure 3. That measured of local tap water was around 8. The zeta potential does vary depending on the $\mathrm{nS}$ particle size and concentration, but was not a measurement made within the scope of this study. It has been reported as $-33.4 \pm 1.8 \mathrm{mV}$, around $-30 \mathrm{mV}$ for $10 \mathrm{~nm}$ particles, or less than $40 \mathrm{mV}$ for $50-80 \mathrm{~nm}$ silica particles at a concentration of $0.1 \mathrm{~g} / \mathrm{L}$ (Bihari et al. 2008; Sieger et al. 2004; Bizi 2012). Based on these reports, the zeta potential of the nS-distilled water solution in this study could be assumed in the range of -30 to $-40 \mathrm{mV}$. As indicated earlier, nanosilica becomes electrostatically unstable in dispersion when the absolute value of the zeta potential approaches or drops below $30 \mathrm{mV}$. Furthermore the mechanical blending agitates the particles and their frequency of collision and interaction which could facilitate more agglomeration.

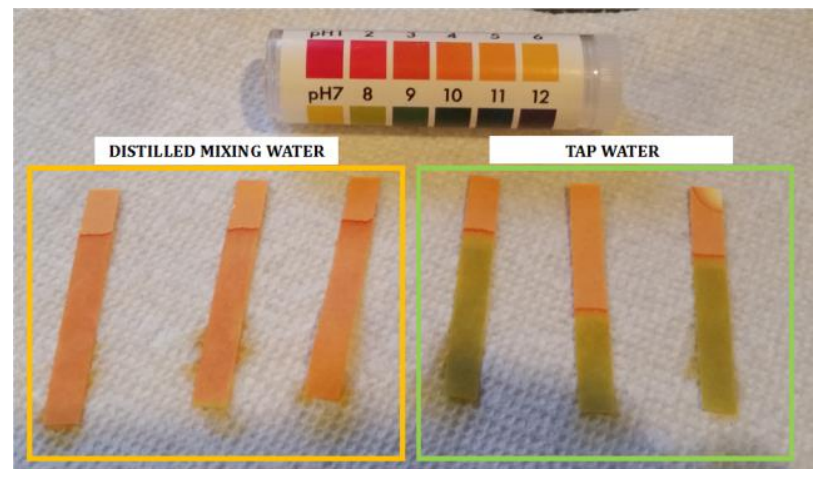

Figure 3. Test Strip pH Measurements of Mixing Water vs Tap Water 
Although the zeta potential was not tested for the nS used in this study, to confirm agglomeration of the $\mathrm{nS}$ when mixed in with the distilled water, samples of the dry $\mathrm{nS}$ used in the study were submitted for laser diffraction particle analysis along with samples of the $\mathrm{mS}$, cement $\mathrm{L}$, and cement M. Prior to taking each measurement, the $\mathrm{nS}$ was ultrasonically mixed with the distilled water for 1 minute, the same period the $\mathrm{nS}$ was dispersed with the mixing water in a blender for the mortar mixtures. As evident in Figure 4, the average particle size measured for the $\mathrm{nS}$ was 6 to $10 \mu \mathrm{m}$, which was significantly larger than the manufacturer specified $\mathrm{nS}$ particle size of $0.015-0.20 \mu \mathrm{m}$. Results of this test confirmed that even with the ultrasonic means of agitating the distilled water suspension, the dry $\mathrm{nS}$ tested in this study tended to agglomerate in clusters that were larger than those measured for $\mathrm{mS}$. The laser diffraction results for $\mathrm{mS}$ being similarly tested and prepared, showed smaller particle sizes and exhibited a broader range of size distribution where $84 \%$ of the sample was in the $0.1-1.0 \mu \mathrm{m}$ particle size range. The $\mathrm{mS}$ particle measurements conformed with the $\mathrm{mS}$ manufacturer data and most typical industry reported $\mathrm{mS}$ sizes of equal to or less than $1.0 \mu \mathrm{m}$ (Holland 2005).

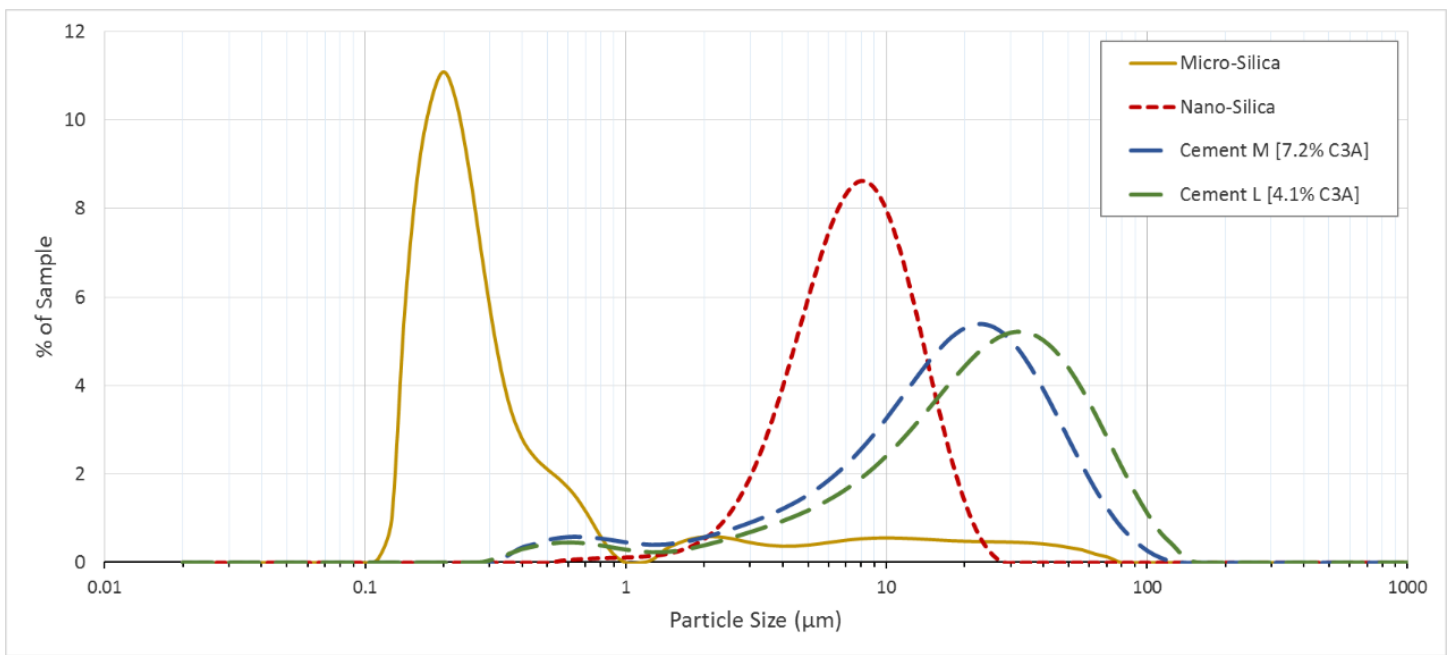

Figure 4. Laser Diffraction Particle Size Analysis of $\mathrm{nS}, \mathrm{mS}$, and Cements $\mathrm{L}$ and $\mathrm{M}$

There is evidence of $\mathrm{nS}$ agglomeration but even in that state, with cement $\mathrm{M}, \mathrm{nS}$ replacement resulted in an improvement in sulfate durability. To better understand the physical and chemical effect the agglomerated $\mathrm{nS}$ had on the mortars, water absorption and RSPT were performed on the control, $3 \% \mathrm{mS}$, $6 \% \mathrm{mS}$, and $6 \% \mathrm{nS}$ mortars. The absorption results as presented in Figure 5 showed that for both cements, the $6 \% \mathrm{nS}$ mortars actually had the smallest measured volume of permeable pore space, $8.30 \%$ for $\mathrm{L} 6 \mathrm{nS}$ and $8.65 \%$ for M6nS. For cement $\mathrm{L}$ that is $13 \%$ less than the $\mathrm{L} 6 \mathrm{mS}$ mortar, and for cement M, M6nS had 19\% less than M6mS. This indicates that the agglomerated dry nS was effective at reducing the porosity of the mortars whether as a filler or through some refinement of the cement paste porosity. Nevertheless the $\mathrm{nS}$ contained mortars still exhibited more expansion than the $\mathrm{mS}$ only and $\mathrm{nS}+\mathrm{mS}$ combination mixtures. 


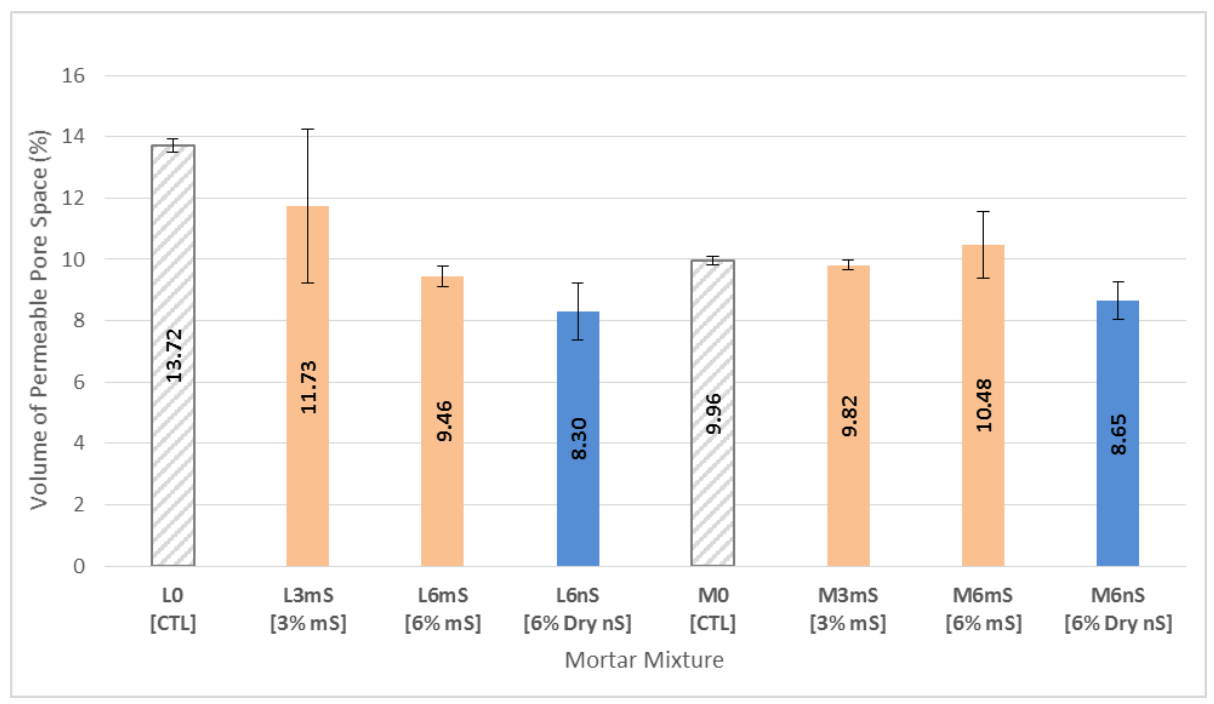

Figure 5. Water Absorption of Select Mortars (error bars represent \pm SD)

The absorption results were not presenting the full story. The results of the RSPT test performed on the same selection of mortars are shown in Figure 6. This 6-hour test performed on 28 days cured mortars measures the penetration rate of sulfate ions which accounts for both the pore structure permeability and the free ion binding capacity. The coulomb charge measurement also accounts for all free ion movement through the mortar which could include the free hydroxide and calcium ions (Stanish et al. 1997). The mobility of these ions would reflect how effective the pozzolans were at reducing the $\mathrm{Ca}(\mathrm{OH})_{2}$ available for reaction with the sulfate ions.

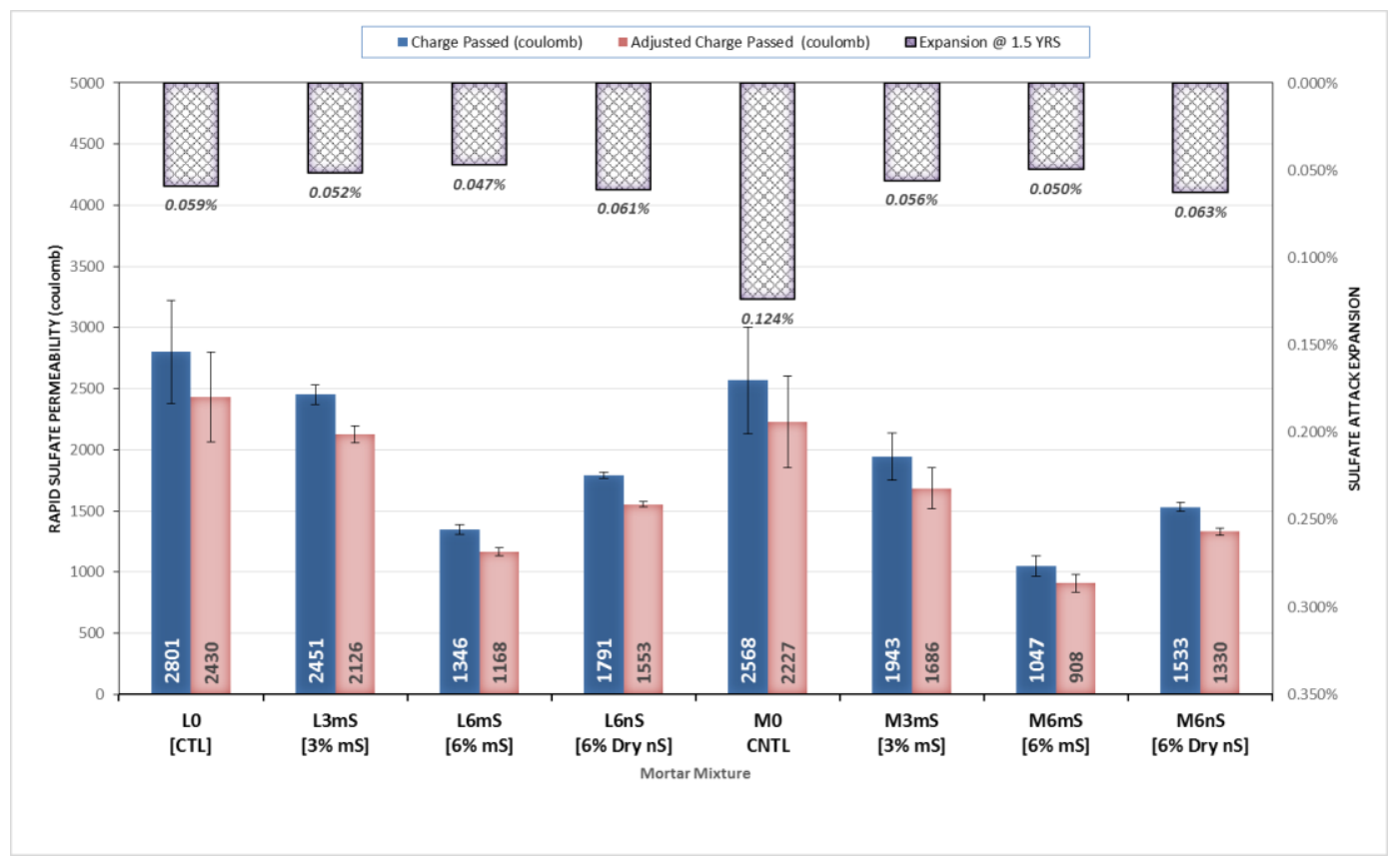

Figure 6. RSPT vs Expansion at 1.5 years of Sulfate Attack for Select Mortar Mixtures (error bars represent \pm SD) 
For cement $\mathrm{L}$, the $6 \% \mathrm{nS}$ mortar L6nS exhibited a higher penetrability compared to the $6 \% \mathrm{mS}$ mortar L6mS which had the lowest coulomb readings. For cement $\mathrm{M}$, the trend was the same. There is a significant decrease in the ion penetrability when the $\mathrm{mS}$ replacement is increased from $3 \% \mathrm{mS}$ to $6 \%$ $\mathrm{mS}$. The combination replacement mortars, although not tested, likely exhibit a similar coulomb reading to the $3 \% \mathrm{mS}$ mortars. The RSPT test correlates the relative sulfate expansion readings of the select mortars tested for RSPT. The sulfate attack expansion readings at 1.5 years for those select mortars are presented in the secondary axis of Figure 6. Although the $\mathrm{nS}$ mortars might be overall less porous according to the absorption test, they allow greater ion penetrability than the $\mathrm{mS}$ mortars. Greater ion mobility in the $\mathrm{nS}$ mortar mixtures indicates the $\mathrm{nS}$ was not as effective as a pozzolan compared to the $\mathrm{mS}$. The higher diffusion rates of the $\mathrm{nS}$ mortars also results in a greater supply of sulfate ions deeper into the mortar to react with hydroxide and calcium ions and generate more expansive ettringite.

The absorption test may indicate permeability in terms of the total permeable void volume but that is not always the case as quality durable concrete could have high porosity yet a low permeability. The pore size distribution, pore interconnectivity, and their tortuosity influence the permeability of the mortars and therefore their response to sulfate attack (Richardson 2002). A mortar may have a higher porosity as measured by absorption, but it may be composed of smaller less interconnected and impermeable voids or larger entrapped air voids that do not facilitate the generation of the expansive stresses that lead to volume instability and cracking from sulfate attack. Pores in the mortar are of different sizes and types and some contribute to permeability and some do not (Neville 1998). To better understand the nature of the silica contained mortars' pore size distribution, cement M mortars M0, M6mS, and M6nS were submitted for mercury intrusion porosimetry (MIP) testing to identify the effects of the $\mathrm{mS}$ and $\mathrm{nS}$ used in this study. Those results are presented in Figure 7.

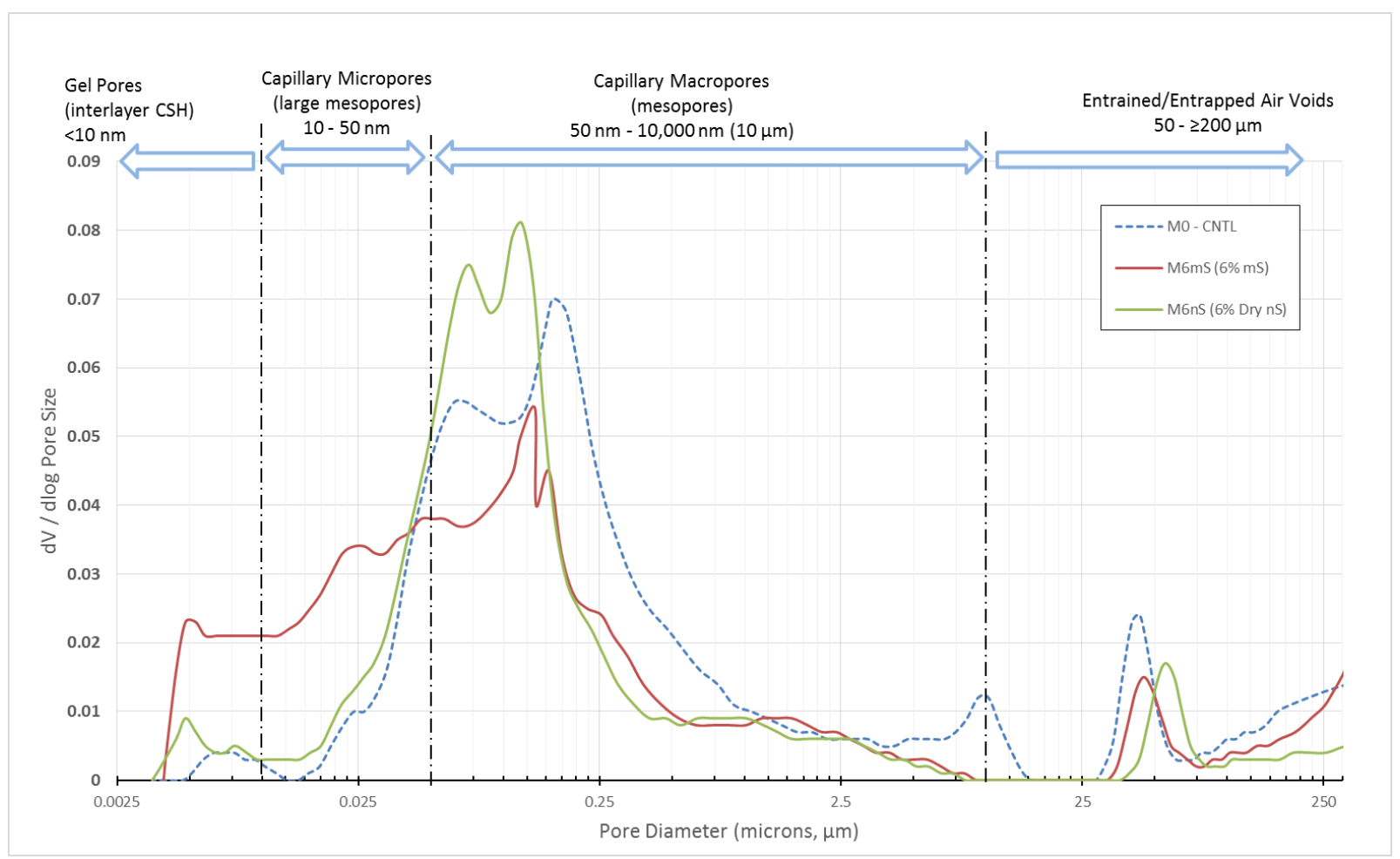

Figure 7. MIP Pore Size Distribution for Cement M Mortars 
Pores in hydrated cement paste have been classified in several categories dependent on their size and influence on the hydrated cement properties. Gel pores are generally less than or equal to $10 \mathrm{~nm}$ and they are integral to the densely layered C-S-H phase; they are considered impermeable and do not contribute to transport processes. Pores ranging from 10 to $50 \mathrm{~nm}$ are considered capillary micropores and although tortuous, these can in small part contribute to permeability. The bulk of permeability and diffusivity occurs in the interconnected capillary macropores ranging from 50-10,000 nm $(0.05$ to $10 \mu \mathrm{m})$ (Tobón et al. 2015; Du et al. 2014; Mindess et al. 2003). The most significant pore refinement is evident in the 6\% $\mathrm{mS}$ contained mortar M6mS. There is a significant shift in its pore size distribution into the gel pore and micropore ranges. The average pore diameter for $\mathrm{M} 6 \mathrm{mS}$ is $30.5 \mu \mathrm{m}$. The results also indicate that the $6 \%$ $\mathrm{nS}$ mortar had a higher volume of pores in the macropore range compared to M6mS and the control M0. This could be attributed to the agglomeration of the dry $\mathrm{nS}$ powder during mixing. Agglomerated nS fails to serve as nucleation sites that can densify the cement paste and as other researchers have found may trap water during mixing that later becomes a porous weak zone ( $\mathrm{Li}$ et al. 2004). There is evidence of this considering that even in agglomerated form, during mixing of M6nS, the demand for HRWRA quadrupled when compared to M6mS to achieve a similar workability and flow. A similar trend could be assumed for the combination mortar $\mathrm{M} 3 \mathrm{mS}+3 \mathrm{nS}$ given that for $\mathrm{M} 3 \mathrm{mS}$, no HRWRA was required but 9 grams of HRWRA were necessary for the combination mixture. The total mercury intrusion volume measured for M0, M6mS, and M6nS was $0.082 \mathrm{~cm}^{3} / \mathrm{g}, 0.0808 \mathrm{~cm}^{3} / \mathrm{g}$, and $0.0687 \mathrm{~cm}^{3} / \mathrm{g}$, respectively. These intrusion volumes correlate with the trend observed with absorption. The mixture with nS might have the lowest total void volume, but most of it is concentrated in the capillary macropore range of pore sizes which negatively impacts the mortar's permeability.

Compressive Strength. Four cubes of the sulfate exposed and four cubes of the moisture room cured mixtures for each cement type were tested in compression at the 28 days, 12, 26, and 52 weeks (1 year). The results for the 26 and 52 week testing of cement $\mathrm{L}$ and cement $\mathrm{M}$ are presented in Figure 8 and Figure 9, respectively. The strength ratio added as the secondary y-axis represents the compressive strength of the sulfate solution exposed samples over that of the cure room counterparts. When over the 1.0 line, it indicates that the average compressive strength of the sulfate exposed samples was higher than that of those tested from the curing room for that particular mortar mixture. Since almost all sulfate solution-to-moist room cured mortar strength ratios were greater than 1, except for L3mS at 52 weeks, there was no evidence of strength loss due to sulfate attack. Other researchers have reported an increase of strength due the filling and compaction effect of the sulfate attack related expansive compounds such as ettringite (Rundong et al. 2010). Upon a longer exposure to sulfate attack, when available pores are filled, the expansive compounds may begin developing micro-cracks that can reverse the trend between the sulfate and curing room samples. 


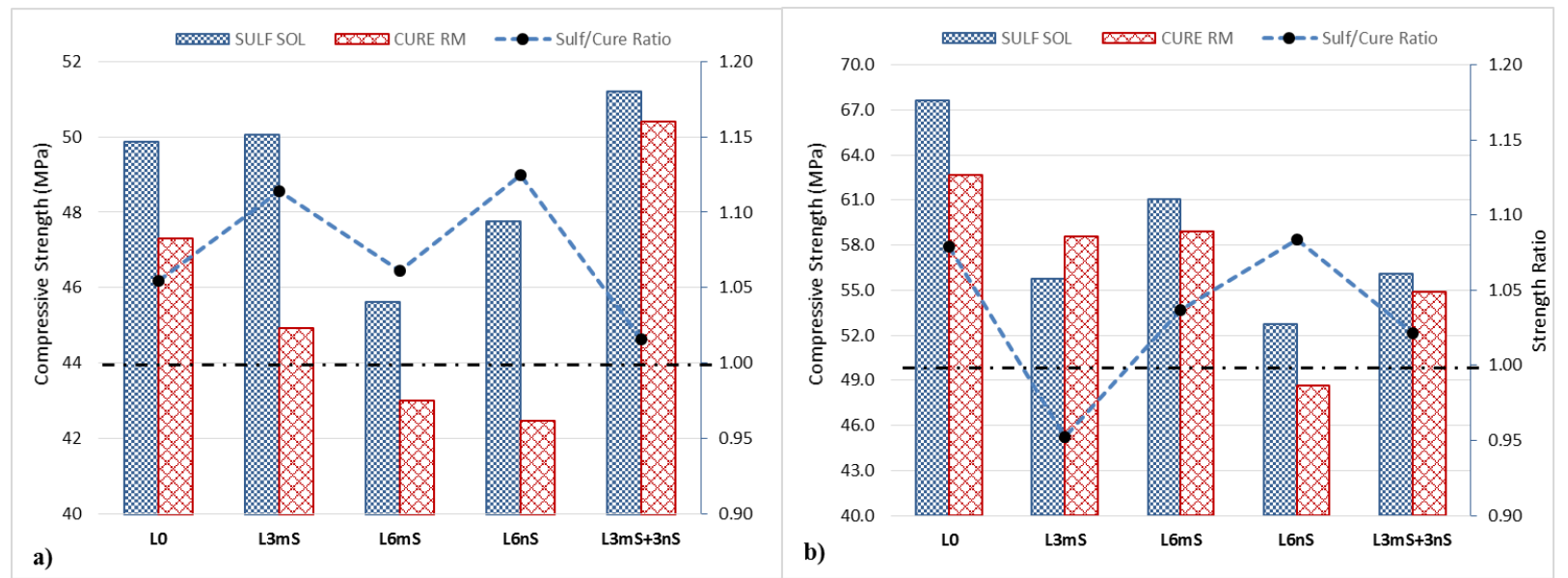

Figure 8. Cement L Mortar Cube Compressive Strengths at, a) 26 Weeks, b) 52 Weeks

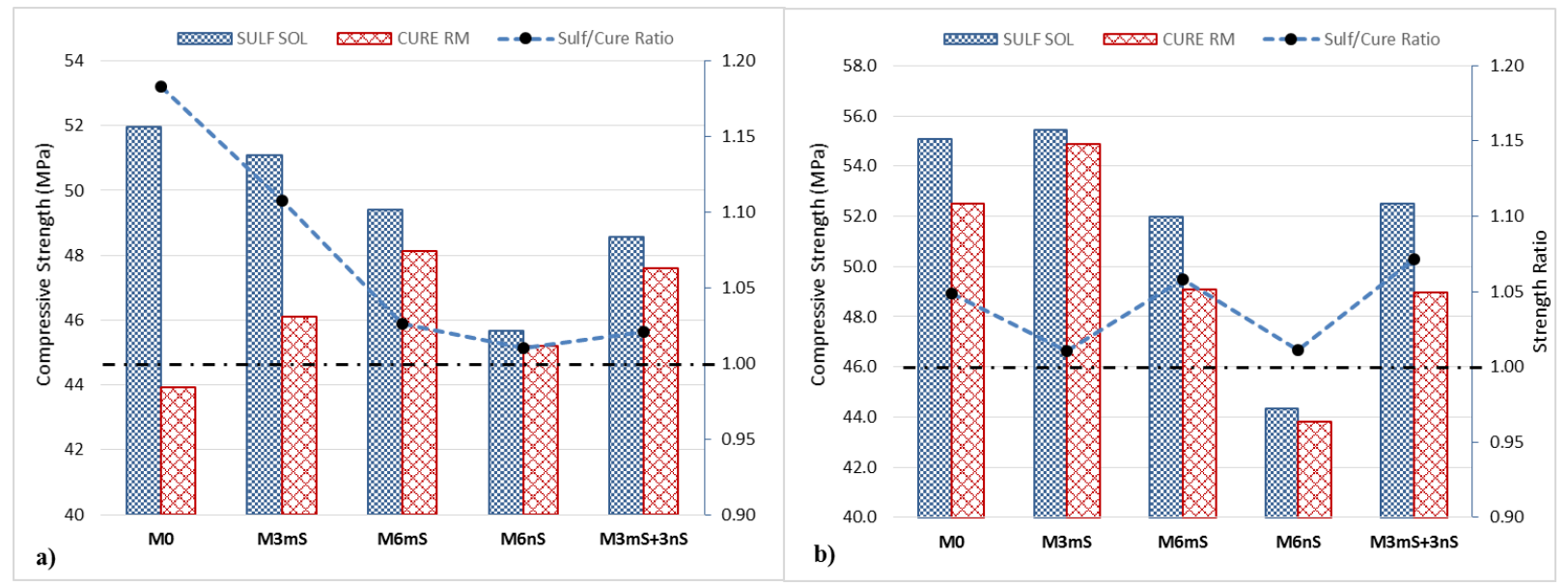

Figure 9. Cement M Mortar Cube Compressive Strengths at, a) 26 Weeks, b) 52 Weeks

In terms of comparing strength, the combination silica mixtures $\mathrm{M} 3 \mathrm{mS}+3 \mathrm{nS}$ and $\mathrm{L} 3 \mathrm{mS}+3 \mathrm{nS}$ outperformed the $6 \% \mathrm{nS}$ mortars both at 26 and 52 weeks. The compression strengths of the $6 \% \mathrm{nS}$ mortars for both cements are the lowest at 52 weeks indicating that the agglomerated $\mathrm{nS}$ weakened the cement paste matrix in comparison to the control and other silica replacement mixtures. The compressive strength measurements at 52 weeks for $\mathrm{L} 3 \mathrm{mS}$ and $\mathrm{L} 3 \mathrm{mS}+3 \mathrm{nS}$ were similar in nature and those of $\mathrm{M} 3 \mathrm{mS}$ are higher that $\mathrm{M} 3 \mathrm{mS}+3 \mathrm{nS}$, indicating that the additional $3 \% \mathrm{nS}$ for cement $\mathrm{M}$ had a negative effect. This further supports the hypothesis that in the combination mortar most of the beneficial effects due to the silica content stems from the $3 \% \mathrm{mS}$ portion.

\section{CONCLUSION}

The authors set out to determine if combined $\mathrm{nS}$ and $\mathrm{mS}$ contained mortars would exhibit superior sulfate durability over comparable mortars mixtures featuring either only $\mathrm{nS}$ or $\mathrm{mS}$ cement replacement. The outcomes of this study were as follows: 
- $\mathrm{M} 3 \mathrm{mS}$ performed almost as well as the combination mortar $\mathrm{M} 3 \mathrm{mS}+3 \mathrm{nS}$ which suggests that most of the beneficial contribution to sulfate resistance in the combination mortar stems from the $\mathrm{mS}$ replacement when poorly dispersed dry $\mathrm{nS}$ is used. The positive contribution of the agglomerated $\mathrm{nS}$ replacement might only be that of reducing the overall availability of $\mathrm{C}_{3} \mathrm{~A}$ by reducing the cement content by another $3 \%$.

- With a sulfate resistant cement, increasing the $\mathrm{mS}$ dose resulted in diminishing returns as the smaller dose of $3 \% \mathrm{mS}$ is almost as effective as doubling it. Similarly to the moderate $\mathrm{C}_{3} \mathrm{~A}$ cement, combining agglomerated dry $\mathrm{nS}$ with $\mathrm{mS}$ is not preferable to pure $\mathrm{mS}$.

- The results also indicated that the $6 \% \mathrm{nS}$ mortar had a higher volume of pores in the macropore range of the pore size distribution that are conducive to permeability and diffusivity compared to M6mS and the control. The authors believe this is attributed again to the agglomeration of the dry $\mathrm{nS}$ powder during mixing. The agglomerated $\mathrm{nS}$ failed to serve as nucleation sites that could densify the cement paste and may have trapped mixing water within the agglomerates during hydration that later resulted in weak and permeable zones. This was supported by the RSPT testing and the observed high HRWRA demand of the agglomerated $\mathrm{nS}$ considering that the $\mathrm{nS}$ was not well dispersed and not exhibiting the desired high surface area.

- The compressive testing results also indicated that, given the poor performance of the $6 \% \mathrm{nS}$ replacement mortars, and the comparable performance between the $3 \% \mathrm{mS}$ and combination mixtures after 1 year curing or sulfate exposure, most of the beneficial effects due to the silica content for the $\mathrm{mS}+\mathrm{nS}$ mixtures is contributed by the $\mathrm{mS}$ when paired with agglomerated $\mathrm{nS}$.

Considering the many forms and gradations of commercially available nano and micro-silica, the effect of $\mathrm{nS}+\mathrm{mS}$ combination mixtures on resistance to sulfate attack warrants more research. Further testing of mortars with combined $\mathrm{mS}$ and $\mathrm{nS}$ cement replacement, where the $\mathrm{nS}$ is in a better dispersed form, such as a verifiable stabilized aqueous solution, is recommended by the authors. Nanosilica that better exhibits its high surface area and aggressive pozzolanic nature through its dispersed nanoscale particles, possibly will better pair with $\mathrm{mS}$ and more effectively resist sulfate attack than when either silica is applied individually.

\section{REFERENCES}

ACI Committee 201, 2008. 201.2R-08 Guide to Durable Concrete, Farmington Hills, MI.

Bibby Scientific, Technical Note T11-001: pH of Distilled Water, Available at: http://www.stuartequipment.com/adminimages/t11_001_ph_of_distilled_water.pdf [Accessed April 7, 2016].

Bihari, P. et al., 2008. Optimized dispersion of nanoparticles for biological in vitro and in vivo studies. Particle and fibre toxicology, 5, p.14.

Bizi, M., 2012. Stability and flocculation of nanosilica by conventional polymer. Natural Science, 4(6), pp.372-385.

Campillo, I., Dolado, J.S. \& Porro, A., 2004. High-Performance Nanoestructured Materials for Construction. In W. Z. Peter J M Bartos, John J Hughes, Pavel Trtik, ed. Nanotechnology in Construction. The Royal Society of Chemistry, pp. 215-225.

CCAA, 2011. Technical Note: Sulfate-Resisting Concrete, Australia. 
Du, H., Du, S. \& Liu, X., 2014. Durability performances of concrete with nano-silica. Construction and Building Materials, 73, pp.705-712.

Hewlett, P.C. \& Massazza, F., 2003. Lea's Chemistry of Cement and Concrete. Lea's Chemistry of Cement and Concrete, pp.471-635.

Holland, T.C., 2005. Silica Fume User's Manual. FHWA-IF-05-016, p.194.

ISO 14887, 2000. ISO 14887 Sample Preparation-Dispersing Procedures for Powders in Liquids. ISO, 2000.

Jiang, J., Oberdörster, G. \& Biswas, P., 2009. Characterization of size, surface charge, and agglomeration state of nanoparticle dispersions for toxicological studies. Journal of Nanoparticle Research, 11(1), pp.77-89.

Kosmatka, S.H. \& Wilson, M.L., 2016. Design and Control of Concrete Mixtures 16th Editi., Skokie, Illinois: Portland Cement Association.

Li, H. et al., 2004. Microstructure of cement mortar with nano-particles. Composites Part B: Engineering, 35(2), pp.185-189.

Mehta, P.K., 1975. Evaluation of Sulfate-Resisting Cements by a New Test Method. October, 72(10), pp.573-575.

Mindess, S., Young, F.J. \& Darwin, D., 2003. Concrete 2nd Editio., Upper Saddle River, NJ: Pearson Education, Inc.

Neville, A.M., 1998. Properties of Concrete 4th ed., New York: John Wiley \& Sons, Inc.

Quercia, G. \& Brouwers, H.J.H., 2010. Application of nano-silica (nS) in concrete mixtures. 8th fib PhD Symposium in Kgs, Lyngby, Denmark.

Richardson, M.G., 2002. Fundamentals of Durable Reinforced Concrete, New York, NY: Spon Press.

Rundong, G. et al., 2010. Deterioration Mechanisms of Sulfate Attack on Concrete under Alternate Action. Journal of Wuhan University of Technology-Materials, pp.355-359.

Said, a. M. et al., 2012. Properties of concrete incorporating nano-silica. Construction and Building Materials, 36, pp.838-844.

Senff, L. et al., 2010. Effect of nanosilica and microsilica on microstructure and hardened properties of cement pastes and mortars. Advances in Applied Ceramics, 109(2), pp.104-110.

Shih, J.-Y., Chang, T.-P. \& Hsiao, T.-C., 2006. Effect of nanosilica on characterization of Portland cement composite. Materials Science and Engineering: A, 424(1-2), pp.266-274.

Sieger, B.H. et al., 2004. Controlling Surface Composition and Zeta Potential of Chemical Vapor Synthesized Alumina-Silica Nanoparticles. Chemical Vapor Deposition, 10(2), pp.71-76.

Singh, L.P. et al., 2013. Beneficial role of nanosilica in cement based materials - A review. Construction and Building Materials, 47, pp.1069-1077.

Skalny, J., Marchand, J. \& Odler, I., 2002. Sulfate Attack On Concrete, London and New York: Spon 
Press.

Sobolev, K. \& Gutiérrez, M.F., 2005. How nanotechnology can change the concrete world. American Ceramic Society Bulletin, 84(10), pp.14-18.

Stanish, K.D., Hooton, R.D. \& Thomas, M.D.A., 1997. Testing the Chloride Penetration Resistance of Concrete: A Literature Review, Toronto, Ontario, Canada.

Taurozzi, J.S., Hackley, V. a \& Wiesner, M.R., 2011. Ultrasonic dispersion of nanoparticles for environmental, health and safety assessment--issues and recommendations. Nanotoxicology, 5(4), pp.711-29.

Tobón, J.I., Payá, J. \& Restrepo, O.J., 2015. Study of durability of Portland cement mortars blended with silica nanoparticles. Construction and Building Materials, 80, pp.92-97.

Winter, N.B., 2012. Understanding Cement, Woodridge, UK: WHD Microanalysis Consultants Ltd. 